Original Article

\title{
Effects of Additional Agitation Process on the Spectrophotometric Profiles of Homeopathic High Dilutions
}

\author{
Luis Gabriel Piñeros*, Luis Miguel Pombo, Claudia Delgado, Jonth Flechas, María Camila Mejía, Paola \\ Borrego \\ Fundación Universitaria Juan N. Corpas. Grupo de Investigación en Farmacología Vegetal y Terapéuticas Alternativas. \\ Carrera $111 \mathrm{~N}^{\circ}$ 159A-61, Bogotá-Colombia. \\ *Corresponding author: luis.pineros@juanncorpas.edu.co
}

\begin{abstract}
Introduction: Conventional homeopathy advocates giving 10 strokes (agitation/succussions) to a prescription bottle containing liquid dilution, before taking it. To scientifically support such activity, it must be based on studies on the physicochemical aspects of the memory of water and agitated water chains, supplemented with spectrometry.

Objective: To analyze spectrometric profiles of homeopathic high dilutions, comparing additionally agitated and non-agitated dilutions, and to define differences according to each dilution's kingdom.

Methodology: Homeopathic dilutions were prepared using a ratio of 1:100 obtaining dilutions from $1 \mathrm{cH}$ to $15 \mathrm{cH}$. Measurements of absorbance of $15 \mathrm{cH}$ dilutions were performed at $340 \mathrm{~nm}$ and $200 \mathrm{~nm}$, with and without additional agitation.

Results: Statistically significant differences were found between agitated and non-agitated dilutions ( $\mathrm{p}<0.05$ ) for Apis mellifica, Bufo rana, and Calcium iodatum, with a decrease in the mean value of absorbance (340 nm) in agitated solutions. For Arnica montana, Matricaria chamomilla, Coffea arabica, Pulsatilla nigricans, Calcium iodatum and Natrum muriaticum, the absorbance values increased; these values decreased for Apis and Bufo. In addition, measurements were performed with a shorter wavelength $(200 \mathrm{~nm})$; it was observed that there are significant differences for all homeopathic dilutions studied.
\end{abstract}

Additionally, when comparing the mean values of the absorbance for each kingdom, and observing the agitation factor, a statistically significant difference was found in the animal kingdom $(\mathrm{p}<0.05)$, having lower absorbance for agitated dilutions.

Conclusion: Comparisons of the spectrometric profiles of agitated and non-agitated solutions allow to observe that there is a difference of the absorbance when comparing a previously agitated solution and a solution with no agitation before taking it.

Keywords: homeopathic dilutions, spectrometry, agitation, succussion, water molecules

\section{OPEN ACCESS}

Cite as: Piñeros LG, Pombo LM, Delgado C, Flechas J, Mejía MC, Borrego P. Effects of Additional Agitation Process on the Spectrophotometric Profiles of Homeopathic Solutions. Int J High Dilution Res. 2016;15(2): 10-21 


\section{Introduction}

Conventional homeopathy has maintained certain standards when it comes to specifying how to take prepared and dispensed medications in liquid dosage forms, normally in drops. One of these methods is to give the bottle 10 energetic shakes (agitated strokes/succussion) on the palm, as a condition prior to taking each homeopathic stimulus dose. This practice was advocated by Samuel Hahnemann, the founder of homeopathy, in the Organon of Medicine, specifying that for repeated doses of a homeopathic medication, the next dose should be modified slightly with each instilling, ensuring a speedy recovery, between 8 and 12 succussions $^{1}$. Few clinical studies to assess effects of homeopathic medicines refer to the recommendation to give 10 strokes to the bottle on the palm of the hand 2,3 .

Throughout the years, a lot of research, writings and publications have been carried out regarding the physicochemical nature of ultrahigh dilutions (UHD) helping in the approach to the understanding of homeopathy. We must emphasize the classic works of Jacques Benveniste on basophils degranulation by IgE in UHD and more than 200 experiments in mice and pigs, obtaining significant effects using ten agonists in UHDs, and also reporting cardiac effects observed by a French team of independent pharmacologists ${ }^{4}$.

Luc Montagnier complemented Benveniste's research about water memory and digital biology, achieving the transmission of deoxyribonucleic acid (DNA) progressively diluted by water nanostructures oscillations; this result was obtained by diluting the DNA of viruses and bacteria to dilution number 30 (which corresponds to the $30 \mathrm{cH}$ according to the method used), depositing the corresponding vials on an electrical device through which a $7 \mathrm{~Hz}$ frequency was passed, making it capable of capturing electromagnetic signals (EMS) which perpetuate DNA information ${ }^{5}$. At the same time, Chaplin points out the fact that the memory of water requires two processes: the dilution and the amplification of signals ${ }^{6}$, which in the case of homeopathy, is obtained as a result of the succussion process.

Madeleine Ennis and M. Robert Froid, who had no relationship with homeopathy, included four research laboratories in France, Italy, Belgium and Holland, observing the effects of ultra-diluted histamine solutions in leukocytes related to inflammation; and Masaru Emoto, even with highly controversial results for his claims, conducted interesting researches on water crystals. On the other hand, the study also highlighted the implicit

OPE ACCESS

Cite as: Piñeros LG, Pombo LM, Delgado C, Flechas J, Mejía MC, Borrego P. Effects of Additional Agitation Process on the Spectrophotometric Profiles of Homeopathic Solutions. Int J High Dilution Res. 2016;15(2): 10-21 
semiotic process in the phenomena associated to high dilutions of Georghe Jurj at West University, Timisoara 7 .

In a paper regarding the role of defining the structure and the plausibility of homeopathy, homeopathic medication comparisons were made with different dilutions, specifically using Natrum muriaticum and Nux vómica $6 \mathrm{cH}, 12 \mathrm{cH}$ and $30 \mathrm{cH}$; these two remedies in the same dilutions were compared, and comparisons were made with and without succussions showing UV spectrum differences between the remedies at the same dilution and among the dilutions. The researchers concluded that under succussion conventional procedures, it is important to observe that considerable pressure (about 10 kbar) may be generated because of agitation. Likewise, the differences in UV spectrum can be attributed to variations in the intra and intermolecular association of the solutions and the process of generating transient and stable nanobubbles ${ }^{8}$.

Another very important work is the one related to the memory of water and homeopathy, describing local and non-local interactions, its quantum and philosophical explanations, as well as "clusters" or icosahedrons formed in water in its condensed structure, approaching to the concepts of the wave - particle duality of quantum theory 9 .

Moreover, the chains of water molecules that facilitate proton transfer in hydrophobic proteins and interaction of proteins with molecular signals in water and their chains (clusters) were studied, considering that UHDs act as the body information network, explaining the extreme sensitivity of biological systems to exogenous and endogenous signals, approaching to the theories of "hormesis" and the paradoxical pharmacology 10,11 .

As a complement, the concept of "dissipative structures" produced in water through the process of succussion, leads towards the explanations on the ability of water to retain a wavelength at a more complex level than the "simple" idea of a chaotic "cluster"12.

Taking into account this background information and considering that in homeopathic clinical practice it is common to recommended shaking homeopathic dilutions, we hypothesized that there are physical differences between an additionally succussed remedy and one that does not require additional succussion. The aim of this study is to analyze the spectrophotometric profiles of UHDs, comparing recently agitated and non-agitated dilutions, and to define

\section{OPEN ACCESS}

Cite as: Piñeros LG, Pombo LM, Delgado C, Flechas J, Mejía MC, Borrego P. Effects of Additional Agitation Process on the Spectrophotometric Profiles of Homeopathic Solutions. Int J High Dilution Res. 2016;15(2): 10-21 
differences according to each dilution's kingdom.

\section{Materials and methods}

\section{Mother tinctures}

Mother tinctures (MT) of Arnica montana (HPRS Class C); Pulsatilla nigricans (HPRS Class C); Apis mellifica (HAB Group 4B); Coffea arabica (HAB Group 4A); Chamomilla (Matricaria chamomilla) (HPRS Class C) and Natrum muriaticum 2cH were imported from Buenos Aires, Argentina, produced by Farmacia Homeopática Cangallo; whereas, Bufo rana $2 \mathrm{cH}$ and Calcium iodatum MT were imported from Germany and produced by Staufenpharma Göppingen.

\section{Sample Preparation}

Homeopathic dilutions were prepared by the Hahnnemanian method using a ratio of 1:100 obtaining dilutions from $1 \mathrm{cH}$ to $15 \mathrm{cH}$, according to the German Pharmacopoeia13; distilled and deionized water was used to perform this process with a disinfection stage using a dual UV lamp and under an electrical conductivity of $1.8 \mu \mathrm{S} / \mathrm{cm}$. Each dilution was subjected to an agitation process (100 hits) in a homeopathic agitator supplied by MEDICOR.

\section{Spectroscopic measurements}

In order to determine the maximum absorbance wavelength of all MT (Arnica montana, Pulsatilla nigricans, Apis mellifica, Coffea arabica, Matricaria chamomilla and Calcium iodatum) and the first available dilutions in our laboratory (Natrum muriaticum $2 \mathrm{cH}$ and Bufo rana $2 \mathrm{cH}$ ) in the range of near-ultraviolet and visible spectroscopy, we used a spectrophotometer with Elisa Accu Reader M965 (Photometric accuracy: $<0.2 \% \mathrm{CV}$ from 0 to $2.0 \mathrm{AU}$; $<0.5 \%$ from 2.0 to $3.0 \mathrm{AU}$ ) plates at the Basic Sciences Laboratory at Fundación Universitaria Juan N. Corpas; 340, 405, 450, 490, 520, 550, 600 and $650 \mathrm{~nm}$ filters were used and also a solvent control line with ethanol extraction was conducted to establish the net absorbance.

Additionally, measurements to the $15 \mathrm{cH}$ dilutions with five replicates were performed at $340 \mathrm{~nm}$ (Accu Reader M965) and $200 \mathrm{~nm}$ in a UV/VIS spectrometer Perkin Elmer Lambda 10 (Photometric accuracy: \pm 0.003 $\mathrm{AU}$ ) located in the Instrumental Chemistry Laboratory at Universidad Distrital Francisco José de Caldas. Ten additional shakes (succussions) were applied to these dilutions $(15 \mathrm{cH})$ and the measurements at the previously mentioned wavelengths were repeated.

\section{Statistical analysis}

Absorbance values were expressed as mean +/- SEM. In order to determine if there are

\section{OPEN ACCESS}

Cite as: Piñeros LG, Pombo LM, Delgado C, Flechas J, Mejía MC, Borrego P. Effects of Additional Agitation Process on the Spectrophotometric Profiles of Homeopathic Solutions. Int J High Dilution Res. 2016;15(2): 10-21 
statistically significant differences, a paired $\mathrm{t}$ Student test was used, with GraphPad Prism 6.0 software. Results were considered significant at $\mathrm{p}<0.05$. To establish if there are statistically significant differences among the absorbance, grouped by kingdom, and discriminated by the agitation factor, a twoway ANOVA with a Tukey post-hoc analysis was performed. Results were considered significant at $\mathrm{p}<0.05$.

\section{Results}

For all mother tinctures (MT): Arnica montana, Pulsatilla nigricans, Apis mellifica, Coffea arabica, Matricaria chamomilla and Calcium iodatum, and for the second dilutions: Natrum muriaticum 2cH and Bufo rana $2 \mathrm{cH}$, it was found that the maximum absorbance was $340 \mathrm{~nm}$ in a range of $340 \mathrm{~nm}$ to $650 \mathrm{~nm}$. It is observed that A. Montana, $M$. chamomilla and P. nigricans have high absorbance values, $A$. mellifica and $C$. arabica show intermediate values; B. rana, C. iodatum, and $N$. muriaticum have the lowest values, as shown in Figure 1.
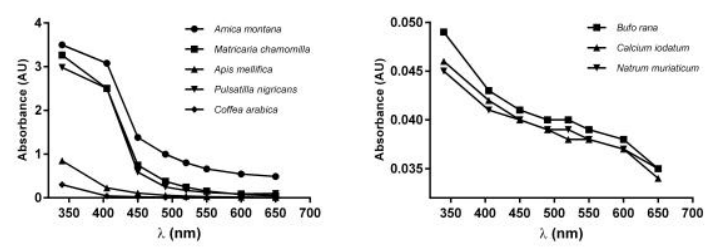

A spectral scanning was carried out for six MT and two $2 \mathrm{cH}$ dilutions, two of them belonging to the animal kingdom, four to the vegetal kingdom and the other two to the mineral kingdom. The maximum absorbance for all MT, was found at $340 \mathrm{~nm}$; A. montana, M. chamomilla and A. mellifica showed absorbance $>3 \mathrm{AU}$; for all the others, the value was < 1 AU. For A. montana, M. chamomilla and $P$. nigricans MT, the absorbance had a decreasing abrupt slope change between 400 and $450 \mathrm{~nm}$, but only for $A$. montana, the absorbance values remained near to $1 \mathrm{AU}$ until $650 \mathrm{~nm}$ (Figure 1).

The mean values of absorbance were observed at $340 \mathrm{~nm}$ of $15 \mathrm{cH}$ dilutions with and without succussion of different homeopathic preparations (Fig. 2). Statistically significant differences $(\mathrm{p}<0.05)$ for A. mellifica B. rana and C. iodatum were observed; they showed a decrease in the mean value of absorbance in succussion solutions (10 strokes). In contrast to the previously mentioned no differences were observed for $M$.chamomilla, A. montana, $P$. nigricans, C. arabica and $N$. muriaticum. It was noted, however, that there was a slight increase in the absorbance value for $M$. chamomilla, A. montana, P. nigricans and $C$. arabica.

\section{OPEN ACCESS}

Cite as: Piñeros LG, Pombo LM, Delgado C, Flechas J, Mejía MC, Borrego P. Effects of Additional Agitation Process on the Spectrophotometric Profiles of Homeopathic Solutions. Int J High Dilution Res. 2016;15(2): 10-21 
Figure 2. Mean values of absorbance at $340 \mathrm{~nm}$ of $15 \mathrm{cH}$ dilutions with additional succussion (S) and without succussion (NS)
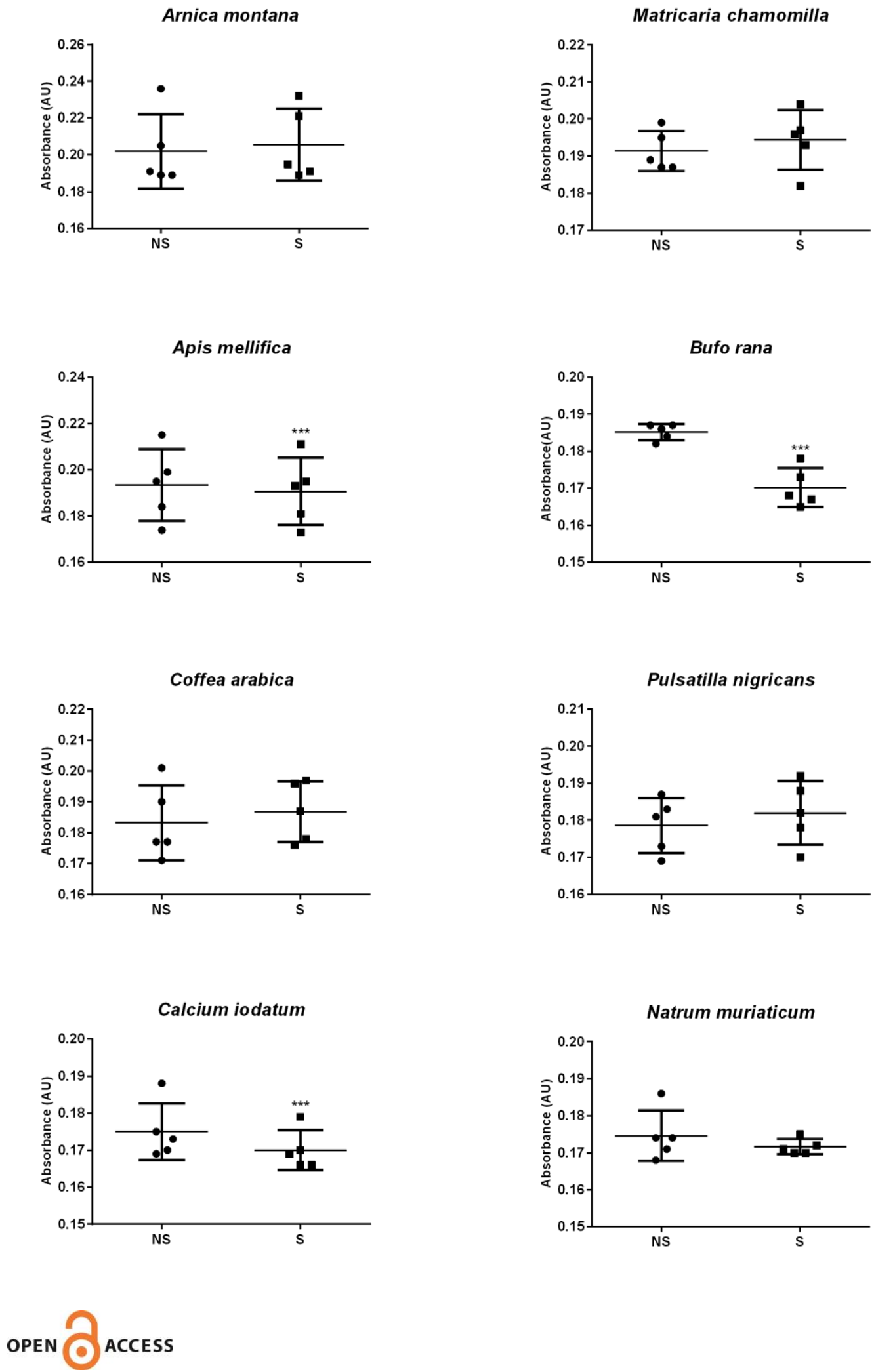

Cite as: Piñeros LG, Pombo LM, Delgado C, Flechas J, Mejía MC, Borrego P. Effects of Additional Agitation Process on the Spectrophotometric Profiles of Homeopathic Solutions. Int J High Dilution Res. 2016;15(2): 10-21 
Figure 3. Mean absorbance values $(200 \mathrm{~nm})$ with $15 \mathrm{cH}$ dilutions with additional succussion (S) and without succussion (NS) of different homeopathic preparations.
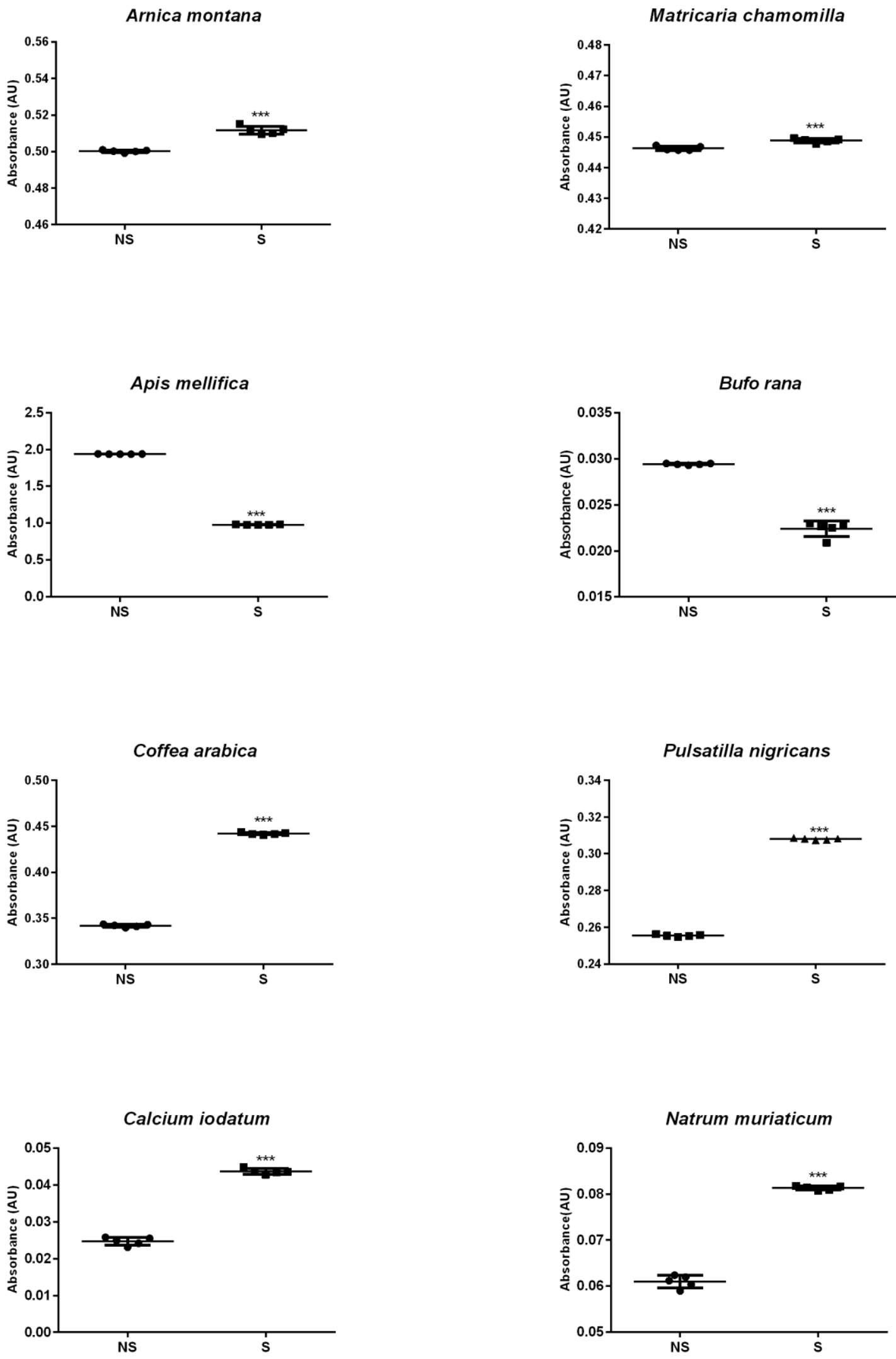
Figure 4. Comparis on of the mean absorbance values by kingdom with additional succussion (S) and without succussion (NS) process.

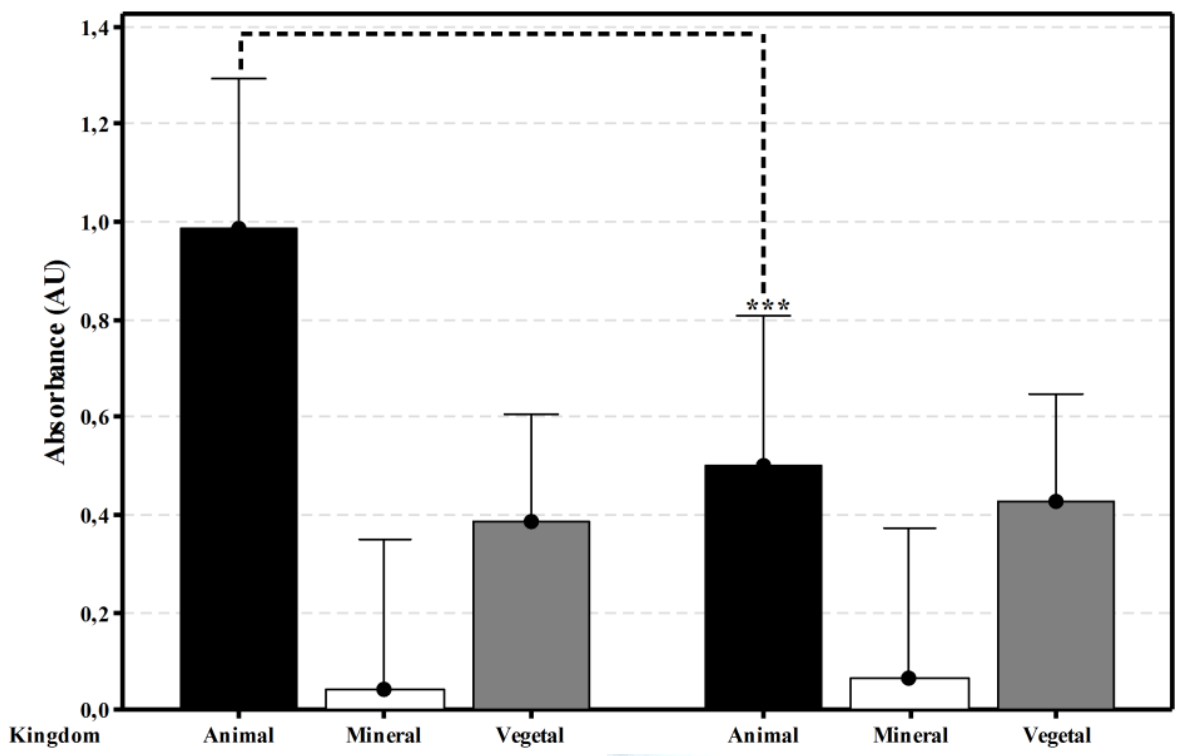

Homeopathic dilutions $(\mathbf{1 5} \mathrm{cH})$

\begin{tabular}{lllllll} 
& $\boldsymbol{N S}$ & $\boldsymbol{S}$ & $\boldsymbol{p}$ & $\boldsymbol{N S}$ & $\boldsymbol{S}$ & $\boldsymbol{p}$ \\
\hline $\boldsymbol{A . ~ m o n t a n a}$ & 0,2020 & 0,2056 & 0,3602 & 0,5002 & 0,517 & 0,0007 \\
\hline $\boldsymbol{M}$. chamomilla & 0,1914 & 0,1944 & 0,3513 & 0,4403 & 0,4488 & 0,0002 \\
\hline $\boldsymbol{A}$ mellifica & 0,1934 & 0,1906 & 0,0086 & 1,938 & 0,9786 & $<0,0001$ \\
\hline $\boldsymbol{P}$. nigricans & 0,1786 & 0,1820 & 0,1008 & 0,2555 & 0,3080 & $<0,0001$ \\
\hline $\boldsymbol{C}$ arabica & 0,1832 & 0,1868 & 0,2413 & 0,3419 & 0,4421 & $<0,0001$ \\
\hline B. rana & 0,1852 & 0,1702 & 0,0031 & 0,0294 & 0,0224 & $<0,0001$ \\
\hline $\boldsymbol{C}$. iodatum & 0,1750 & 0,1700 & 0,0089 & 0,0247 & 0,0436 & $<0,0001$ \\
\hline $\boldsymbol{N}$ muriaticum & 0,1746 & 0,1716 & 0,2844 & 0,0610 & 0,0813 & $<0,0001$ \\
\hline
\end{tabular}

Table 1: Absorbance mean values of different homeopathic dilutions $(15 \mathrm{cH})$ at $340 \mathrm{~nm}$ and $200 \mathrm{~nm}$.

In Figure 3, it was observed that there are significant differences for all homeopathic dilutions studied. It was found that in the succused group absorbance values were higher for A. montana, M. chamomilla, $C$. arabica, P. nigricans, C. iodatum and $N$. muriaticum. These values were lower compared to the unsuccused ones for $A$. mellifica and B. rana. In addition, measurements were performed on a more accurate equipment and at a shorter wavelength (200 nm). At this particular wavelength, the mean absorbance, without additional succussion, varies within the range between $0.024 \mathrm{AU}$ (C. iodatum) and 1.938 AU (A. mellifica); with additional succussion between $0.022 \mathrm{AU}$ (B. rana) and 0.978 AU (A. mellifica).

OPEN ACCESS

Cite as: Piñeros LG, Pombo LM, Delgado C, Flechas J, Mejía MC, Borrego P. Effects of Additional Agitation Process on the Spectrophotometric Profiles of Homeopathic Solutions. Int J High Dilution Res. 2016;15(2): 10-21 
The absorbance values were measured for the homeopathic dilutions at 340 and $200 \mathrm{~nm}$, with and without additional succussion (Table 1, Figure 2, Figure 3). At $340 \mathrm{~nm}$, the mean absorbance, without additional succussion, fluctuates between $0.174 \mathrm{AU}(N$. muriaticum) and $0.202 \mathrm{AU}$ (A. montana); with additional succussion between $0.170 \mathrm{AU}(C$. iodatum) and 0.205 AU (A. montana).

Finally, when comparing the absorbance values of the homeopathic solutions by kingdoms $(15 \mathrm{cH})$ at $200 \mathrm{~nm}$, and taking into account the agitation factor, we found that in both groups, with and without succussion, the highest mean absorbance values were observed of the animal kingdom dilutions, $0.983 \mathrm{AU}$ and $0.500 \mathrm{AU}$, respectively, with statistically significant differences $(\mathrm{p}<0.05)$.

The lowest absorbance means were obtained in the dilutions from minerals; nondifferences were found when it compared the absorbance means between mineral and vegetal kingdoms (Figure 4).

\section{Discussion}

In this study we found that the absorbance values of succussed dilutions were higher than non-agitated solutions; comparing the absorbance values by kingdom, the animal kingdom had higher values than the mineral and vegetal kingdoms; finally, statistically significant differences were observed between the UV spectrum of different homeopathic preparations with agitation and without agitation. These results coincide with other studies $8,13,14$.

Wolf et al. considered that, apparently, the homeopathic preparations have a higher absorbance compared to non-homeopathic dilutions; in their analysis, a UV (160-200 $n m)$ spectrum was used and the absorption corresponds to the transition between the electron in the bound state and the unbound state $\left(\mathrm{n} \rightarrow \sigma^{*}\right)$ of unpaired electrons localized on the oxygen atom of the water molecule ${ }^{14-16}$. Even if the remedies we chose for this research are all homeopathic preparations, we found out that additionally, succussed dilutions had a higher absorbance for A. montana, M. chamomilla, C. arabica, $P$. nigricans, C. iodatum and N. muriaticum. For this case, results were similar to the ones obtained by the author recently mentioned. However, as the absorbance was lower for $A$. mellifica and B. rana, these last results did not corroborate Wolf's findings.

For the authors, it is important to point out that remedies from the same kingdom have a similar spectrophotometric profile. Boericke, at the beginning of the $20^{\text {th }}$ century, published one of the few studies which correlated nature kingdoms and clinical actions; he

\section{OPEN $\rightarrow$ ACCESS}

Cite as: Piñeros LG, Pombo LM, Delgado C, Flechas J, Mejía MC, Borrego P. Effects of Additional Agitation Process on the Spectrophotometric Profiles of Homeopathic Solutions. Int J High Dilution Res. 2016;15(2): 10-21 
stated the similarities in the therapeutic response of homeopathic remedies of the plant kingdom that coincide in their chemical composition, as in the case of Aconitum, Pulsatilla and Cimicifuga (belonging to the Ranunculaceae) or the case of Ignatia and Nux vomica, plants that come from the same order and share the alkaloid strychnine ${ }^{17}$.

We consider these absorbance differences between additionally agitated and nonagitated dilutions as a very important finding, given that these spectrophotometric changes could corroborate homeopathy's agitation method.

In light of the foregoing, this study shows the different amount of light absorbed by a solution that is succussed prior being used, from the solution that is not shaken before its application. Yet, considering that in some cases the absorbance decreases and in other it rises, it may not be inferred whether the effect of shaking before consuming the remedy has a higher or better effect for therapeutic purposes or not.

\section{Conclusion}

The comparison of spectrometric profiles of agitated and non-agitated solutions allows us to demonstrate the physical changes that result from the action of using kinetic energy to impact the solution.
The use of energy derived from measuring the amount of light absorbed by a solution at a specific wavelength is an important tool to analyze homeopathic stimuli. In other words, spectrometry is a robust and reliable method for this type of analysis.

Acknowledgments: The authors thank Fundación Universitaria Juan N. Corpas and Universidad Distrital Francisco José de Caldas.

Conflict of Interest: None declared.

\section{References}

1. Hahnemann S, Organon der Heilkunst. [Internet]. 1998. [cited 23 Oct 2015]; pp. 266 - 267. Available from: http://homeoint.org/books/hahorga $\underline{\mathrm{n} / \mathrm{index} . \mathrm{htm}}$

2. Mondéjar M, Amado M. Aplicación de la homeopatía a pacientes fumadores de la localidad "Enrique Varona". Rev Cubana Hig Epidemiol [Internet] 2010 [cited 23 Oct 2015]; 48(3): 253 - 263. Available from: http://scielo.sld.cu/pdf/hie/v48n3/h ie04310.pdf

3. Barcíela J, Cabrera N, de la Torre M, Barrios M. Eficacia del tratamiento homeopático en la neuralgia trigeminal. Archivo Med Camagüey [Internet]. 2002[cited 23 Oct 2015]; 6(7). Available from: 
http://revistaamc.sld.cu/index.php/a

mc/article/view/3247

4. Benveniste J. Defense of diluted water. Nature. [Internet]. 1991[cited 26 Oct 2015]; 353.Available from: http://www.nature.com/nature/jour $\underline{\mathrm{nal} / \mathrm{v} 353 / \mathrm{n} 6347 / \mathrm{abs} / 353787 \mathrm{a} 0 . \mathrm{html}}$

5. Montagnier L, Aissa J, Del Giudice E. DNA waves, and water. J. Phys. [Internet] 2010 [cited 27 Oct 2015].Available from: http://montagnier.org/IMG/pdf/DNA waves and water.pdf

6. Chaplin M. The memory of water: an overview. Homeopathy. [Internet] 2007 [cited 27 Oct 2015]; 96: 143150. Available from: http://www.homeopathyjournal.net/ article/S1475-4916(07)00065-3

7. Jurj G. Decision making and semiotics: A view in homeopathy. Int J High Dilution Res. [the Internet]. 2008 [cited 27 Oct 2015]; 7(23): 103-112. Available from: http://www.feg.unesp.br/ ojs/index. php/ijhdr/article/viewFile/270/346

8. Rao M, Roy R, Bell I, Hoover R. The defining role of structure (including epitaxy) in the plausibility of homeopathy. Homeopathy. [Internet] 2007 [cited 27 Oct 2015]; 96(3): 175 182. Available from: https://www.researchgate.net/public ation/6160174 The defining role of structure including epitaxy in the pl ausibility of homeopathy

9. Milgrom L. Conspicuous by its absence: the Memory of Water, macro-entanglement, and the possibility of homeopathy. Homeopathy. [Internet] 2007 [cited 27 Oct 2015]];96(3): 209-19. Available from: http://www.homeopathyjournal.net/ article/S1475-4916(07)00059-

\section{8/abstract}

10. Bellavite P, Marzotto M, Olioso D, Moratti E, Conforti A. High-dilution effects revisited. 2. Pharmacodynamic mechanisms. Homeopathy. [Internet]. 2014 [cited 11 Nov 2015];103(1):2243. Available from: http://www.homeopathyjournal.net/ article/S1475-4916(13)00066-0

11. Milgrom L. The eternal closure of the biased mind? The clinical and the scientific relevance of biophysics, infinitesimal dilutions, and the memory of water. J Altern Complement Med.2009; 15 (12):1255-1257.

12. Elia V, Napoli E, Germano R. The "Memory of water": an almost deciphered enigma. Dissipative 
structures in extremely dilute

aqueous solutions. Homeopathy.

2007; 96: 163 - 169.

13. GHP German Homoeopathic

Pharmacopoeia. Fifth edition.

Germany: Medpharm Scientific

Publishers; 2003.

14. Wolf $\mathrm{U}$ et al, homeopathic preparations of Quartz, Sulfur, and Cooper Sulfate assesed by UVSpectroscopy. Evid. Based Complement. Alternat. Med. 2011.
15. Zacharias

C. Contaminants in commercial homeopathic medicines. Homeopathy; 1995.

16. Sukul N, Sukul A. High Dilutions Effects: Physical and Biochemical Basis. Springer Netherlands; 2004; pp58- 60 .

17. Boericke W. Principles of Homeopathy. As taught by Hahnemann, and verified by a century of clinical application. 1896; (6): p45.

Received: April 13, 2016. Accepted: June 27, 2016.

(C) International Journal of High Dilution Research.

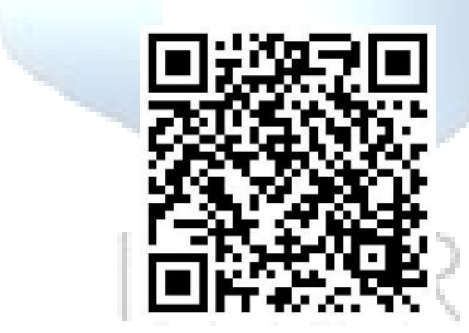

QR code to full article

\section{OPEN ACCESS}

Cite as: Piñeros LG, Pombo LM, Delgado C, Flechas J, Mejía MC, Borrego P. Effects of Additional Agitation Process on the Spectrophotometric Profiles of Homeopathic Solutions. Int J High Dilution Res. 2016;15(2): 10-21 